\title{
К ПРОБЛЕМЕ ЭТНОРЕЛИГИОЗНОЙ САМОИДЕНТИФИКАЦИИ СОВРЕМЕННЫХ ОСЕТИН
}

\section{С.Г. Кцоева}

Религия как наиболее консервативная форма общественного сознания часто выступает в качестве этносохраняющего стержня: господство религиозного сознания в обществе сохраняет его традииионность, поэтому в условиях усиливающегося воздействия глобализационных процессов на массовое сознание, ослабляющего позиции традиционных культур, популярность религии в обществе, стремящемся сохранить свою традиционность, начинает объективно расти. Религиозное мировоззрение современных осетин является конфликтным: среди представителей этноса нет общего мнения относительно религиозной принадлежности народа, его «титульной» религии. Одна часть выступает за концепиию «народного христианства», апеллируя к принятому Аланией в Х в. православию. Другая часть убендена в том, что осетины - носители собственной религии, сохранившей свою самобьтность, несмотря на сильное влияние, которое оказали на нее институциональные религии (в большей степени христианство, в меньшей-ислам). Очевидно, стремлением к возрождению этнической традииионности в современных условиях объясняется тот факт, что в последнее время в осетинском обществе возобладала тендениия возрождения этнорелигиозного традиционализма, которому, однако, также дается неодинаковая оценка: часть осетин считает традиционную осетинскую религию язычеством, другая - категорически с этим не согласна. Затянувшийся спор об осетинском язычестве, по мнению многих представителей этноса, не способствует культурной консолидации народа, $а$ лишь разобщает его перед тицом угроз постиндустриальной стадии развития мира. Что именно является предметом обозначенной дискуссии, и какими соииальными реалиями она порождена? Какова научная основа, которая подведена под заостренные друг против друга точки зрения? Насколько корректно употребление термина «язычество» при характеристике этнических черт религии осетин с научных позиций? Существуют ти в науке альтернативные категории для обозначения данного явления? Ответом на эти, а также ряд других вопросов является настоящая статья.

Ключевые слова: осетины, религия, язычество, религиозная самоидентификация, ретигиозное мировоззрение, этническая религия, народная религия.

Religion as the most conservative form of public consciousness often acts like ethnical core: domination of religious consciousness in the society preserves its traditional character, therefore under the condition of increasing impact of globalization processes on public consciousness, weakening the position of traditional cultures the popularity of religion in the society, that tends to preserve its traditional character, objectively begins to grow. The religious views of contemporary Ossetians are controversial: among the representatives of the ethnos there is no common opinion about the religious affiliation of the people, their "title" religion. One part supports the idea of "national" Christianity appealing to the accepted Orthodoxy in Alanya in the Xth century. The other part is convinced that Ossetians are representatives of their own religion that preserved its originality in spite of the strong influence that the institutional religions had on it (mostly - Christianity, less - Islam). Obviously, the tendency to the revival of ethnical traditionalism in modern traditions is explained by the fact that the idea of the revival of ethno-religious traditionalism, which however is not viewed commonly, has prevailed in the society lately. Some people consider paganism to be the traditional religion of Ossetians. Others strongly disagree. According to the opinion of many ethnical representatives the protracted dispute about the Ossetian paganism does not contribute to the cultural consolidation of people, but only disunites them in the face of the threats in the period of postindustrial development 
of the world. What exactly is the subject of this discussion and what social realities caused it? What is the scientific basis of the strongly rival viewpoints? How right is it to use the term "paganism" characterizing the ethnical features of the Ossetian religion from the scientific point of view? Are there alternative categories in scienceto designate this phenomenon? The answers to these and a number of other questions can be found in this article.

Keywords: Ossetian, religion, heathendom, religious self-definition, religious world view, ethnic religion, folk religion.

...историческое и неисторическое одинаково необходимы для здоровья отдельного человека, народа и культуры. Фридрих Нищие

Осетины - один из наиболее сложных в определении религиозной идентичности этнос. Религиозное мировоззрение осетин является конфликтным: тут имеет место столкновение различных идей, противостояние традиций и новаторства, состязание различных систем ментальности, и даже конфронтация цивилизаций.

Сложные перипетии истории народа, оставившего свой заметный след в истории культур Древности и Средневековья, сковали в причудливый монолитный сплав индоиранское наследство, античное влияние, черты раннего христианства, православие средневековой Византии и грузинское православие, влияние кавказской культурной общности и ислама. Удивительно, но процесс развития религиозного мировоззрения осетин продолжается до сих пор, несмотря на массовое распространение секулярного мышления как маркера информационного общества. Это находит свое подтверждение в активной полемике различных точек зрения не только в среде «высоколобых» интеллектуалов, апеллирующих к фактам исторического прошлого, хорошо ими знаемого, но, что важно, и среди широких слоев обывателей - основных носителей этой самой религиозной традиции - нет единого мнения относительно конфессиональной самоидентификации этноса. Религиозное мировоззрение осетин на данном этапе можно определить как кри- зисное, что, впрочем, свидетельствует об активной вовлеченности народа в этот процесс, стимулирует интерес к обозначенной проблеме и обещает ее неминуемое разрешение в будущем.

Проблема религиозной самоидентификации осетинского этноса видится его представителям очень серьезной в свете обострения вызовов постиндустриального общества и стремительно глобализирующегося мира, которые таят угрозу если не полного исчезновения, то, во всяком случае, значительного ослабевания национальных культур вообще, а малых - в особенности. В этих условиях осетинская религиозная традиция воспринимается осетинами вне зависимости от социальных категорий как важный цементирующий материал, обеспечивающий сохранение национально-культурной идентичности.

Однако ожесточенные споры все же не обеспечивают искомого единства, что значительно ослабляет роль религии как хранителя национальной идентичности в современном осетинском обществе и препятствует реализации ее консолидирующей функции.

Что именно является предметом обозначенной дискуссии, и какими социальными реалиями она порождена? Какова научная основа, которая подведена под заостренные друг против друга точки зрения? Насколько корректно употребление термина «язычество» при характери- 
стике этнических черт религии осетин с научных позиций? Существуют ли в науке альтернативные категории для обозначения данного явления? Постараемся разобраться.

Наверняка каждый житель Осетии, Северной ли, Южной ли, хоть раз да участвовал в полемике по вопросу о том, носителями какой именно религиозной традиции являются осетины. Как правило, в зависимости от ответа на этот вопрос, спорщики делятся на две категории: на тех, кто считает традиционную осетинскую религию язычеством, и тех, кто ее таковой не считает. Аргументами вооружены обе противоборствующие стороны. Первые обосновывают свою позицию наличием различных божеств, объединенных в пантеон («семибожие») и присутствием в культовой практике элементов, отличающихся от культовой практики мировых религий. Их оппоненты, отрицающие язычество у осетин и их предков в принципе (иногда даже в дохристианской индоиранской древности), отстаивают убежденность в их строгом монотеизме. Аргумент: наличие в религиозном сознании веры в «Великого Бога» (Стыр Хуцау). Упомянутые «боги»- и не боги вовсе, а «небесные/святые покровители».

Упомянутый спор длится не одно десятилетие, причем не только на обывательском уровне, но и в ученой среде. Динамика развития научной полемики по данной проблеме, степень разработанности различных точек зрения убедительно и в каком-то смысле исчерпывающе проанализирована М.Э. Мамиевым в его книге «Аланское православие: история и традиция» [1] в разделе «Историографический обзор». Автор книги, отмечая кризисное состояние (правда, в стадии постепенного преодоления [1, 46]) современного изучения осетинского христианства, видит причины кризиса в продолжающемся инертном влиянии со- ветской исследовательской школы, стремившейся к обоснованию исторических процессов с формационных позиций и недооценивавшей роль религии в развитии обществ. М.Э. Мамиев выделяет два направления в рамках советской школы: во-первых - «идеологическую теорию поверхностной христианизации» $[1,45]$ осетин, «которая получила свое окончательное оформление в работах В.А. Кузнецова», и во-вторых - «идеологическую теорию осетинского язычества, являющегося логическим продолжением первой» $[1,46]$. К исследователям, развивавшим первую теорию, помимо упомянутого В.А. Кузнецова, М.Э. Мамиев отнес В.И. Абаева, А.Х. Магометова и др.; вторую - В.Х. Тменова, Б.Х. Биджелова, Ф.М. Таказова и др. Сам автор, как можно догадаться, с идентификацией осетин с язычниками категорически не согласен и является, по-видимому, представителем следующего подхода, где «авторы исходят из изучения древней индоиранской составляющей осетинской традиционной культуры, определяя степень и характер ее взаимодействия с богато представленным христианским компонентом» $[1,44]$. В рамках выделенного третьего направления автор называет ученых В.С. Уарзиати, Р.С. Бзарова, Р.Ф. Фидарова, Т.К. Салбиева.

Характерным является то, что М.Э. Мамиев определяет осетин как этнос в корне православный, объясняя наличие нехристианских элементов в религии и традиционной культуре как следствие естественного процесса адаптации православной ортодоксии к осетинской этнической специфике. Иными словами, он говорит о феномене аланского православия как, скажем, о русском или же греческом православии, что теоретически вполне оправдано [2]. Однако вслед за В.И. Абаевым, М.Э. Мамиев, очевидно, исключает ислам из круга факторов, повлиявших на формирование осетинской 
культурно-религиозной идентичности, считая важным при изучении осетинской религии остановиться на комплексном изучении только трех известных составляющих: индоиранской традиции, православного христианства и кавказского субстрата при неизменном приоритете православной традиции $[1,236]$.

Таким образом, выявилось направление интеллектуалов, считающих православное христианство византийского канона (с вплетенными в нее элементами дохристианских верований и позднейшего влияния автохтонного кавказского субстрата) исконной религией алан/осетин.

Тенденция эта вполне объяснима. Так, по мнению петербургского этнолога С.А. Штыркова, «...национализм создает предпосылки для повышения социальной значимости религии, которая становится одним из главных символов этнической группы (нации). В этих условиях часто происходит национализация мировой религии (так, например, складывается образ православия как квинтэссенции русской культуры и соответственно как традиционной религии русских)» $[3,314]$. Происходит ли сейчас в Осетии реальная «национализация» православия, сказать трудно, на наш взгляд, вообще невозможно, как невозможен тотальный монизм в условиях нарастания постмодернистских процессов, как известно, способствующих религиозной и идеологической атомизации общества.

Несмотря на активное участие Русской православной церкви в общественной жизни Российского государства и ее вполне объяснимое стремление к возрождению православных традиций и их популяризации в том числе и в Осетии, в последнее время в осетинском обществе, тем не менее, возобладала тенденция возрождения этнорелигиозного традиционализма, в чем-то даже враждебного в отношении мировых (институциональных) религий (христианства и ислама), что в свою очередь вызвано уже упомянутым (осознанным или неосознанным) стремлением нации к самосохранению в условиях глобализации. Враждебность эта определена интуитивным страхом этноса «растворить» «свое, родное» в «чужом». По сути это - ментальное противостояние стандартизации и унификации культуры народа и борьба за сохранение собственной самобытности. Эта часть осетин (среди которых также немало интеллектуалов), именуемая в просторечье «традиционалистами» и представляющая противоположное обозначенному выше направлению, упорно борется с «крещением», по их убеждению, совершенно нехристианских национальных традиций.

Приведенный вывод был сформулирован на основе анализа данных неофициального социологического опроса, проведенного нами в соцсетях в рамках ряда популярных осетинских пабликов, a также с использованием традиционного («бумажного») анкетирования, что позволило нам охватить не только городскую и сельскую осетинскую молодежь, но и людей старших поколений, проводящих значительно меньше времени в соцсетях или вовсе в них не зарегистрированных. Общее количество опрошенных составило 1472 человека. В опросник входило пять вопросов с различными вариантами ответов: 1) верите ли вы в Бога?; 2) если Вы считаете себя верующим, то какого вероисповедания Вы придерживаетесь?; 3) исполняете ли Вы религиозные обряды? 4) какая из религий, по Вашему мнению, является наиболее приемлемой для представителей осетинского этноса?; 5) как Вы оцениваете традиционную осетинскую религию? Варианты к последнему вопросу приведем здесь: а) как единобожие (монотеизм); б) как многобожие (политеизм); в) затрудняюсь ответить.

Результаты вполне закономерные: анализ ответов на первый вопрос выя- 
вил рекордный процент верующих осетин - 96 \%. Из них 38\% придерживаются христианства, в подавляющем большинстве православного, 34\% - традиционных осетинских верований, 6\% - ислама. Чрезвычайно интересно, что при ответе на второй вопрос большое количество людей (18\%) отметило два варианта (то есть в качестве своего вероисповедания одним человеком отмечались одновременно православие и традиционные осетинские верования). При этом 40\% отправляет религиозные обряды только по праздникам, 18\% отправляют культ почти полностью, 32\% опрошенных стремятся исполнять большинство религиозных обрядов. $10 \%$ респондентов признались, что не исполняют религиозных обрядов вовсе. Как мы видим, общее количество людей, считающих «внешнюю» сторону религии более или менее важной, составило суммарно 90\%. Этот вывод - важный эмпирический элемент в анализе религиозного мировоззрения современных осетин. Иными словами, 96\% из 100\% = верят в Бога, и 90\% из 100\% = в той или иной мере участвуют в обрядовой практике, что свидетельствует о высокой степени вовлеченности религии в повседневную жизнь современных осетин.

Весьма неожиданными и интересными (при сопоставлении с данными второго вопроса) оказались результаты анализа четвертого вопроса: наиболее приемлемой для представителей осетинского этноса религией 62\% (!) респондентов сочли традиционную осетинскую религию, что выглядит странным, учитывая, что большинство верующих осетин во втором вопросе (38\%) считают себя православными, однако при этом более приемлемой именно для осетин считают традиционную осетинскую религию. Данное обстоятельство подтверждает наш вывод о растущей популярности традиционных осетинских верований. Всего лишь 2\%, проявив последовательность, отметили и тут два варианта (православное христианство и традиционные осетинские верования). За православие в четвертом вопросе проголосовало лишь $18 \%$ респондентов, за ислам - 2\% (что на 2/3 меньше результата, показанного во втором вопросе). 16\% (всего лишь на 2\% меньше в сравнении с отдавшими свой голос за православие) продемонстрировали верность институтам правовой государственности, отвергнув необходимость обязательного соотнесения осетинского этноса с какой-либо конкретной религией, поскольку сочли это вопросом индивидуального выбора.

Наконец, мы подошли к анализу вопроса об оценке самими осетинами традиционной осетинской религии. $60 \%$ охарактеризовали ее как монотеистическую, 16\% - как политеистическую, 24\% затруднились с ее идентификацией в подобном ключе. Интересно другое: из 60\% оценивших осетинские традиционные верования как монотеистические, ровно половина (50\%) - это «традиционалисты», 33,3\% (!) - православные христиане, 3,3 \% - мусульмане, 10\% придерживаются одновременно православия и традиционных осетинских верований, 3,3 \% не отнесли себя ни к какой религии.

Еще раз обратим внимание на то, что треть (!) православных (!) опрошенных оценивает традиционную осетинскую религию как монотеизм, не считая, таким образом, «традиционалистов» язычниками (если понимать язычество как политеизм). Указанное обстоятельство может свидетельствовать о том, что треть респондентов, считающих себя православными, находится под возрастающим влиянием «традиционализма» и не согласна с тем, чтобы религия осетин, пусть даже в своей традиционной форме, считалась язычеством.

Любопытно, что единства нет и среди «традиционалистов»: 16\% из них убеждены в политеистичности своего религи- 
озного мировоззрения. Важно отметить, что этот процент составили в основном люди старшего поколения, чье религиозное мировоззрение формировалось в 50-70-е годы ХХ века. Но почему старшее поколение признает свои верования языческими в отличии от более молодого?

Дело в том, что главным объектом борьбы советской власти в области религии были, как правило, институциональные религии: «...большевики видели своего главного врага не столько в самой религиозной вере, сколько в религиозных институциях. Логика антирелигиозных кампаний сводилась к максимальному ограничению официальной религиозной жизни. Видимо, предполагалось, что если закрыть церкви и запретить деятельность священников, с религией будет покончено. В этих условиях те практики, которые мы бы назвали религиозными - в случае с осетинской культурой это, например, ритуальный пир куыьд и паломничество к святыням-дзуарам - выпадали из поля зрения властей, поскольку не ассоциировались с православной церковью и священниками. Они воспринимались в терминах скорее народного обычая, традиции. Так на некоторое время осетины перестали быть не только христианами, но и язычниками» $[3,312]$. Поэтому в сознании представителей старшего поколения, народная традиция в постсоветский период просто «вернулась на прежнее место», и термин «язычество» в их религиозном мировоззрении, таким образом, лишен отрицательных коннотаций.

Напротив, возрастной состав «традиционалистов-монотеистов» охватывает людей в возрасте в среднем до 60 лет, что указывает на то, что монотеистическое восприятие «традиционной религии» осетин хронологически было сформировано только в перестроечно-постсоветский период, когда провозглашенная свобода совести сняла запрет на религию в российском обществе. Представители этих поколений осетин, таким образом, уже испытывали на себе сильное влияние в первую очередь православного христианства, реже - ислама, жестко противопоставлявших себя язычеству. С точки зрения вероучения обеих религий, язычество - явление крайне одиозное, своеобразная сублимация дикости, примитивности, варварства и прочих характеристик данного синонимического ряда, выраставших из практики многобожия, которое расценивается здесь как непреодолимое препятствие на пути духовного «очеловечивания». Сюда же вплетается еще один миф, сформировавшийся в Европе эпохи колониализма, но живой до сих пор: «язычество - враг цивилизации». Вполне естественно, что сознание, испытывающее на себе воздействие подобных стереотипов, болезненно реагирует на штамп «язычник» в свой персональный адрес.

К интеллектуалам данного мировоззренческого лагеря относился авторитетнейший ученый B.C. Уарзиати. Его симпатии явно на стороне православия, а не «язычества»: это явствует из его сочинений. Так, говоря о разночтениях при определении даты празднования Рождества (Цьпnурс) и Нового года (Ног бон) осетинами, ученый высказывает следующее убеждение: «Мне представляется, что в современных условиях, когда нарастает процесс очищения от всего наносно20 (курсив наш - С.К.), есть насущная потребность объединиться с христианским миром и придерживаться исходной даты Рождества, объявленной с 1991 г. праздничным днем народов Российской Федерации» $[4,28]$.

По всей видимости, под «наносным» B.C. Уарзиати подразумевает «язычество», а духовную ситуацию времени оценивает однозначно положительно в силу того, что православие получило долгожданную поддержку со стороны государства («праздничный день народов 
Российской Федерации»). Добавим, что в своих работах ученый избегает употребления термина «язычество» в отношении религии осетин.

Таким образом, упомянутый латентный конфликт интерпретаций стал важной частью религиозного мировоззрения осетин постсоветского периода.

А корректно ли вообще постулирование традиционной осетинской религии как язычества? Самое время обратиться к теории вопроса.

Согласно всезнающей Википедии, «Язы́чество (от церк.-слав. зы́йы «народы», формы мн. ч. от зы́къ «народ», являющегося калькой с др.-греч. ع̌ $\theta$ vо ) принятый в христианском богословии и частично в исторической литературе термин, обозначающий традиционные и нехристианские религии. В более узком смысле, язычество - политеистические религии. Однако далеко не все «языческие религии» политеистичны. Термин «язычество» происходит из Нового завета, в котором под язычеством подразумевались народы или «языки», противополагаемые первохристианским общинам» [5].

Не существует однозначного общепринятого определения язычества. Приведем несколько смысловых вариантов:

1) формы первобытных религий (анимизм, фетишизм, магия, культ предков, тотемизм и др.), а также религиозные системы цивилизаций древности: Египта, Ассирии и Вавилона, индо-иранских государств, Иудеи, Греции и Рима и т.д.;

2) все не авраамические религии (в трактовке авраамистических религий);

3) все политеистические религии;

4) религия определенного этноса, не относящаяся к мировым религиям, адепты которой могут принадлежать к разным этносам. С этой точки зрения язычеством может быть назван даже иудаизм;

5) идолопоклонство (поклонение творению, а не Творцу). «Если считать почитание изображений Бога поклонением, в этом смысле, например, с точки зрения ислама, языческим может быть названо и христианство» [5];

6) «новые религиозные течения неоязыческого толка (родноверие, ромува, асатру, викка, сейд), реконструирующие верования и возрождающие обряды разных народов, существовавшие у них до распространения всемирных монотеистических конфессий» [5].

7) иноверие, в том числе «монотеистическое».

Как видно из приведенной классификации, она не носит сколько-нибудь научного характера, являясь чисто теологической: любая из авраамистических религий может назвать язычеством все остальные религии, в том числе, авраамистические. Следовательно, научное именование осетин «язычниками» некорректно с собственно научной точки зрения.

Современные западные этнологи все чаще заменяют церковнославянское слово «язычество» понятием «этническая религия». Автора термина установить не удалось. Словосочетание «этническая религия» впервые промелькнуло у Гете в 1821 г. в его педагогическом романе «Годы учения Вильгельма Мейстера» [6]. Понятие «этническая религия» в современной науке явилось нейтральной альтернативой неточным, «чужим», заимствованным из других областей знания дефинициям, часто вводящим в заблуждение и девальвирующим культурное наследие целого ряда народов.

Представители британской этнологической школы - Джон Хиннелз, Джеймс Кокс - использовали термин «этническая религия» при описании различных религий, связанных с теми или иными этническими группами. $\mathrm{C}$ их точки зрения, к этническим религиям, таким образом, относятся известнейшие индуизм, иудаизм, а также японский синтоизм, то есть религиозные системы, обладающие письменной традицией $[7 ; 8]$. 
По мнению представителей немецкой этнологической школы, критерием идентификации этнической религии является ее бесписьменный характер, когда религиозная традиция имеет только устную трансляцию $[9 ; 10 ; 11]$. В этом смысле позиции английской и немецкой школ не совпадают. Тем не менее, термин «этническая религия» методологически давно апробирован европейскими и американскими коллегами. Активно проводятся исследования с целью классификации этнических религий различных народов мира.

Перейдем к анализу близкого по смыслу, но имеющего существенное отличие понятия «народная религия», которую ни в коем случае нельзя путать с термином «этническая религия». Народная религия представляет собой различные формы и проявления религий, отличающихся от официальных систем вероучения и практик институциональных религий (народное христианство, народный ислам и т.д.). Адаптируясь к мировоззрению конкретной этнической общности, любая доктринальная религия часто несколько видоизменяется, приобретая самобытные черты. Таким образом, упомянутые «традиционалисты» с научной точки зрения являются носителями этнической религии осетин, а православные осетины - это, безусловно, адепты народного православия. К подобному выводу в оценке осетинской народной религии пришел уже упоминавшийся здесь М.Э. Мамиев: «...очень часто не принимается в расчет объективное наличие этнических особенностей внутри православного христианства, которые, не затрагивая догматической части вероучения, находят реализацию в календарной, обрядовой и других сферах религиозной жизни, создавая свою, неповторимую православную культуру, которая в свою очередь способствует сохранению идентичности создавшего ее народа. Этот универсаль- ный принцип в полной мере относится к аланской христианской истории» $[1 ; 236]$.

До М.Э. Мамиева традиционную осетинскую религию назвал «народным христианством» В.С. Уарзиати: «С 40-х годов XVIII века Осетия активно входит в круг внешнеполитических интересов России. В 1774 году Осетия добровольно входит в состав Российского государства. Естественно, что эти и последующие исторические события способствовали генерации христианских идей, хотя долгое время они продолжали бытовать в форме своеобразного “народного христианства"» $[4,23]$. Таким образом, мы видим, что концепция «осетинского народного православия», сформулированная в изысканиях ряда ученых, приобрела своих сторонников, выведя генеральную полемику на уровень научного обсуждения.

Подведем некоторые итоги.

Религиозная самоидентификация осетин в настоящее время сложна и конфликтна. Заметная ее активизация, диктуемая усугублением постмодернистских тенденций, обостряет споры по вопросу «кто мы?». Именование спорящих сторон «язычниками» и «не язычниками» (за исключением случаев, когда дискуссия ведется в богословских кругах) не корректно с точки зрения достижений современной этнологии и религиоведения, более чем три десятилетия назад официально и безболезненно отказавшихся от термина «язычество» при характеристике каких-либо религий. Таким образом, неавраамистический компонент религии осетин также не может идентифицироваться как языческий с научных позиций. Широко применяются термины «этническая религия» [ethnic religion] и «народная религия» [folk religion], разные по смыслу, несмотря на корреляцию перевода.

Между тем, градус религиозности современного осетинского общества очень высок: 96\% опрошенных осетин верят 
в Бога, 90\% из которых с различной долей регулярности участвуют в культовой практике. Анализ конфессиональной принадлежности верующих выявил своеобразную «вилку»: 38\% - православные vs $34 \%$ - «традиционалисты», что, скорее всего, свидетельствует о возрастании социального влияния осетинской этнической религии. Парадоксальную ситуацию со всей очевидностью выявил анализ четвертого вопроса анкеты: $62 \%$ из 100\% опрошенных убеждены в оптимальности осетинской этнической религии для осетин, несмотря на то, что большой процент респондентов, разделивших это убеждение, позиционирует себя в качестве православных христиан.

Общий анализ эмпирических данных на основе изложенной теоретической базы выявил ряд конфессиональных групп:

1) православные христиане, полностью отказывающиеся от этнической составляющей религии (16\%);

2) адепты народного православия (38\%, из которых 20\% - определяют себя как православных, но практикуют этнорелигиозные культы, а 18\% - это те, кто отнес себя одновременно к двум конфессиям - православному христианству и этнической религии осетин);

3) протестанты (как правило, отделяют христианские традиции от этнорели- гиозных, предпочитая игнорировать последние) (2\%);

4) мусульмане, придерживающиеся «чистого» ислама (без этнорелигиозных элементов) (3\%);

5) мусульмане, не отказывающиеся от участия в осетинской этнорелигиозной культовой практике (3\%);

6) адепты осетинской этнической религии (34\%).

Как мы видим, искомого религиозного единства, действительно нет. Данное обстоятельство не может не вносить некоторую религиозную напряженность, которая, впрочем, не представляет сколько-нибудь серьезной социально-политической угрозы для нормального существования и развития осетинского этноса и его культуры, поскольку осетинская ментальность, как правило, чужда религиозного фанатизма, в особенности, его крайних проявлений. Это доказывается всем ходом истории осетинского народа.

В известном смысле активность религиозной жизни в Осетии определена именно этим упомянутым спором, поэтому, несмотря на негативные его оценки, противоборствующие стороны являют собой диалектическое единство, наличие которого обеспечивает не только выживание этноса в постмодерной действительности, но и его дальнейшее поступательное развитие. 


\section{Примечание}

В переводах Библии этим словом называются нехристианские народы за пределами христианской ойкумены и в противоположность христианам. В древнерусском языке слово обозначало «народ» вообще.

1. Мамиев М.Э. Аланское православие: история и традиция. М., 2014.

2. Белова О.В. Христианство народное // Славянские древности: Этнолингвистический словарь в 5 тт. под ред. Н.И. Толстого. М., 2012.

3. Штырков С.А. «Народная религия осетин»: судьба концепта в XIX-XX вв. // Радловский сборник. Научные исследования и музейные проекты МАЭ РАН в 2007 г. СПб., 2008. С. 309-317.

4. Уарзиаты В.С. Праздничный мир осетин. Владикавказ, 1995.

5. Язычество [сайт]. URL: https://ru.wikipedia.org/wiki/

6. Karl Otto Conradi: Goethe - Leben und Werk: Zweiter Teil: Summe des Lebens. S. Fischer, 2015. Google-Books-Ansicht [электронный ресурc]. URL: https://forum. golem. $>$ wissenschaft $>$ /

7. Hinnells John R. The Routledge companion to the study of religion. Routledge, 2005.

8. Cox James L. From Primitive to Indigenous: The Academic Study of Indigenous Religions. Aldershot: Ashgate, 2007.

9. Udo Tworuschka: Ethnische Religionen In: Monika und Udo Tworuschka (Hrsg.): Bertelsmann-Handbuch Religionen der Welt. Bertelsmann, Gütersloh, Muenchen, 1992.

10. Thomas Schweer: Stichwort Naturreligionen. Heyne, Muenchen, 1995.

11. Karl R. Wernhart: Ethnische Religionen - Universale Elemente des Religiösen. Topos, Kevelaer, 2004. 